\title{
Development of Small Scale Soft X-ray Lasers: Aspects of Data Interpretation.
}

\author{
C.H. Skinner, D. Kim, D.Voorhees, and S. Suckewer ${ }^{\dagger}$
}

Princeton Uniwersity Plasma Physics Laboratory.

Princeton, N.J. 08543

\begin{abstract}
The widespread application of soft $x$-ray laser technology is contingent on the development of small scale soft $x$-ray lasers that do not require large laser facilities. Progress in the development of soft $\mathrm{x}$-ray lasers pumped by a Nd laser of energy 6-12J is reported below. Some aspects of data interpretation and gain measurements in such systems are discussed.
\end{abstract}

\section{DISCLAIMER}

\begin{abstract}
This report was prepared as an account of work sponsored by an agency of the United States Government. Neither the United Siates Government now any agency thereur, nor any of their employees, makes any wattanty, express or implied. or assumes any lega! liability of responsibijity for the accuracy, completeness, or usefulness of any information, apparatus, product, or process diselosed, or reptesents inat its use would not infringe privately owned rights. R-ference herein to any specific commercial product, process, or cervice by trade name, trademark. manufacturer, or otherwise does not necessarily constitute or imply its endorsement, recommendation, of fayoring by the United States Government of any agency thereof. The views and opinions of authors expressed hereio du not necesssrily state or reflect those of the United Slates Government or any agency thereof.
\end{abstract}

+ also at Mechanical and Aerospace Engineering Dept., Princeton University 


\section{MiTRODUCTION}

The field of $\mathrm{x}$-ray laser technology has recently matured to the stage where the application of these devices to fields such as $x$-ray microscopy is underwayl and commercial units are being planned with a view to industrial applications such as microlithography. A critical factor in such development is the scale and hence cost of these devices. The collisionally pumped soft $x$-ray laser in neon-like ions, developed at Livermore ${ }^{2}$. requires a large scale laser facility such as Novette or Nova to create a plasma of appropriate conditions. A $3 m J .182 \AA$ soft $x$-ray laser based on a recombining plasma was developed at Princeton ${ }^{3}$ with an efficiercy almost 2 orders of magnitude higher than the collisionally pumped case. However the pump laser required, a $300 \mathrm{~J} \mathrm{CO}_{2}$ laser, was still large. In order to increase the output energy and efficiency of the $182 \AA$ soft $x$-ray laser we have been developing soft $x$-ray amplifiers. A gain of $8 \mathrm{~cm}^{-1}$ has been measured in a $3 \mathrm{~mm}$ long carbon piasma transversely pumped by a 3nsec Nd laser pulse of energy $25 \mathrm{~J}$, of which only $15 \mathrm{~J}$ impinged un the target ${ }^{4}$. We have also demonstrated amplification of $4.5 \mathrm{~cm}^{-1}$ in a plasma pumped by only $6 \mathrm{~J}^{5}$. In this paper we will present the initial gain measurements at $182 \AA$ in a carbon plasma pumped by a $6 \mathrm{~J}$ laser pulse. We will also present some measurements showing a non-linear rise of intensity with length in an Al plasma pumped by a 6 or $12 \mathrm{~J}$ laser pulse . We will discuss aspects of data interpretation and gain measurement in such systems.

\section{AMPLIFICATION AT 182Aं WITH A GJ PUMP LASER}

In this section, we present gain measurements on the CVI $182 \AA$ transition in a carbon plasma produced with a $6 \mathrm{~J}, 3 \mathrm{nsec} \mathrm{Nd:glass} \mathrm{laser} \mathrm{pulse.}$ The experimental set-up was the same as presented in an earlier paper ${ }^{4}$. 
Figure 1 shows the rotatable target system used. A $67-\mathrm{cm}$ focal-length spherical lens and $450 \mathrm{~cm}$ focal length cylindrical lens were operated in a slightly defocussed arrangement to produce a $\sim 200 \mu \mathrm{m} \times 5 \mathrm{~mm}$ line-focus on a length-varying cylindrical target. The target lengths used in this experiment were $1,2.5$, and $4.5 \mathrm{~mm}$ (limited by the diameter of the access ports in the target chamber). A $0.8 \times 2 \mathrm{~mm}$ slot in a mask located $1.5 \mathrm{~cm}$ away from the target in the axial direction, selected a limited spatial region which was viewed by an axial soft $\mathbf{x}$-ray spectrometer equipped with a multichannel detector. In the experiments the slot was placed in such a way that it selected a spatial region $0.0-0.8 \mathrm{~mm}$ from the target surface.

Figure 2 shows the intensity variation of the CV $135 \AA$. OVI $173 \AA$, CVI $182 \AA$, and $C V 186 \AA$ lines with respect to the plasma length using a $6 \mathrm{~J}$, 3 nsec. laser pulse. No stainless steel blade or magnetic field was used. The CVI $182 \AA$ line ( 3-2 transition) increased non-linearly while the CVI $135 \AA$ (4-2 transition) and some other lines increased linearly as expected from optically thin spontaneous emission from a homogeneous plasma of length equal to the length of the target. This was a clear Indication of gain on the $182 \AA$ line. The difference in the length dependence of the $182 \AA$ and $i 35 \AA$ lines here is very important ( the contribution of the 4 th order of the CVI $33.74 \AA$ line to $135 \AA$. even for the $1 \mathrm{~mm}$ plasma, was negligible due to the large opacity of this line). The data were fitted by a nonlinear regression model $^{6}$ which performed a leastsquare fit of the data to the relation:

$$
I(L)=\frac{(\exp (G L)-1)^{3 / 2}}{(G L \times \exp (G L))^{1 / 2}}
$$


This describes the output intensity of a Doppler-broadened, homogeneous source of amplified spontaneous emission of gain-length product GL. The fit yielded a value of the gain of $4.5 / \mathrm{cm}$ on the CVI $182 \AA$ line and of $0.5 / \mathrm{cm}$ on the CVI $135 \AA$ line (see fig. 3). This result augers well for the commercial availability in the near future of relatively inexpensive soft $x$-ray lasers for a variety of novel applications.

\section{EXPERIMENTS ON ALUMINIUM PLASMAS, ASPECTS OF DATA INTERPRETATION}

In the above experiment the plasma length was limited to $4.5 \mathrm{~mm}$ by the internal diameter of the ports available in the target chamber inside the magnet. A new target chamber was constructed in which plasmas of length of $1 \mathrm{~cm}$ or more could be produced. This system also had much more flexibility for positioning and angular adjustment of the target and detector (Fig. 4 ). In this section we present some results from this system showing an non-linear increase of intensity with length of AIX and AlXI lines in an aluminum plasma. The lithium sequence ions such as AlXI were first used in soft $\mathrm{x}$-ray laser development by Jaegle and coworkers? ${ }^{7}$ however the present work on aluminium plasmas pumped with a low energy Nd laser was primarily stimulated by the surprising results of Hara et.al. ${ }^{8}$ indicating gain on alinost all AlX and ALXI lines observed. It was a simple task to repeat the experiments of Hara et. al. by changing the target material to aluminium.

A Nd glass laser, operated at $6 \mathrm{~J}$ or $12 \mathrm{~J}$, was brought to a line focus by a combination of 4 lenses. Two spherical lenses with a combined focal length of $60 \mathrm{~cm}$ and two cylindrical lenses produced a sharp line focus $12 \mathrm{~mm}$ long with a width of $50 \mu \mathrm{m}$ (FWHM) on a rotatable aluminium target with sectors of differing 
length $(2,6,10 \mathrm{~mm})$. Axial emission was detected by a soft $\mathrm{X}$-ray multichannei spectrometer "SOXMOS" 9. SOXMOS was attached to a rotatable arm pivoted under the target so that the angle it vewed could be varied by $\pm 2^{\circ}$ with respect to the target. The target assembly was on a platform that could be rotated $\pm 2^{\circ}$ around a vertical axis so that by combining the two motions. emission over $a \pm 4^{\circ}$ axial range in the horizontal plane could be recorded. This system was designed to allow the most precise alignment of the target with respect to the spectrometer and also enable the detection of a stimulated soft $\mathrm{X}$-ray beam that had been deviated from the nominal axial direction by refraction in the plasma. A slot with open area $3 \mathrm{~mm}$ high and $0.35 \mathrm{~mm}$ wide was placed on axis $4 \mathrm{~cm}$ from the target to limit the view of the spectrometer. The position :f the slot could be adjusted to view regions of the plasma at different distances from the target surface.

In the experiment a search for gain was performed by varying the experimental parameters (including the target length) and looking for conditions in which the intensity of candidate lines increased with length at a rate that was faster than linear. A faster-than-linear rise of intensity with length is commonly regarded as conclusive evidence for stimulated emission.

Figure 5 shows axial spectra of AlrV, OVI, AlX, and ALXI lines at $2 \mathrm{~mm}$ and $10 \mathrm{~mm}$ target lengths. A dramatic increase of intensity of the AIX and AiXI lines is seen with the $10 \mathrm{~mm}$ target as compared to $2 \mathrm{~mm}$, while the AIJV and OVI lines show a sub-linear increase. Figure 6 shows peak intensities taken at 2, 6 , and $10 \mathrm{~mm}$ target lengths and a curve fit to the data. The theoretical fit was derived from a nonlinear regression model ${ }^{6}$ as in the CVI case. In general the transition linewidth will be a convolution of Stark and Doppler broadening but for the present purposes we have used the gain equation based on the Doppler broadening. 
A higher laser energy was used in order to increase the output intensity. Data taken at $12 \mathrm{~J}$ is shown in Figs. 7 and 8 . Here the increase with length is even more dramatic, for instance the AlXI $141 \AA$ (3s-4p) intensity increases from $2 \mathrm{~mm}$ to $10 \mathrm{~mm}$ by a factor of $\mathrm{x} 50$ and is an excellent fit to the gain equation for

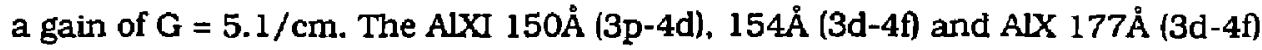
lines also show a length dependence which is a very close fit to the gain equation at comparable values of gain. Similar results were obtained for the

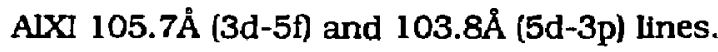

The emission from the plasma was recorded on a time-resolving streaked spectrometer ${ }^{10}$, "TGSS " placed on-axis, on the opposite side of the plasma to the spectrometer: SOXMOS. A free standing gold transmission grating with a $3000 \AA$ period and $250 \mu \mathrm{m}$ entrance slit, dispersed the axial plasma emission along the entrance slit of an $\mathbf{x}$-ray streak camera. The entrance slit was $12 \mathrm{~mm}$ long, lmm wide, and coated with a $200 \AA$ thick aluminium photocathode. This grating, streak camera arrangement resulted in a source-size-limited spectral resolution for these experiments of approximately $3 \AA$. The spectral range of the instrument extended from $I 10 \AA \AA$ to $190 \AA \AA$.

The streaked image was amplified by an image intensifier and recorded on calibrated Trix film placed in contact with the output of the image intensifier. The sweep speed was $1.25 \mathrm{nsec} / \mathrm{mm}$ resulting in a temporal resolution of approximately $0.25 n s e c$. Figure 9 shows detailed time histories of the $154 \AA$ and $162 \AA$ emission taken with $12 \mathrm{~J}$ of laser energy. The emission had a total duration of 6 nsec.

\section{Data Analysis}

There are some unexpected features to the data in Figs 5-8. First of all, every ALX and AlXI !ine observed, without exception, showed a non-linear 
increase with length. In general the gain coefficient depends on the factors shown in equation 2:

$$
G=\frac{1}{8 \pi c} \frac{\lambda^{4}}{\Delta \lambda} \quad g_{i} A_{i j k} \quad\left\{\frac{N_{i}}{g_{i}}-\frac{N_{k}}{g_{k}}\right\}
$$

Here $G$ is the gain coefficient, and $\lambda$ the wavelength. $g$ is the statistical weight. A 4 the radiative transition probability and $\mathrm{N}$ the population of the upper level $i$ and lower level $k$. The highest gain was expected on the 3-4 transition with the largest gA value (3d-4f at 154Å), however the data shows high gain on all the AlXI and AlX lines observed, similarly to reference 8 . Particularly surprising was the strong increase apparent on the AlXI $] 41$ i line. which has a gA value much lower than the $150 \AA$ and $154 \AA$ transitions. The time history observed with the streak camera showed no difference between the time evolution at $154 \AA$ and the continuum background at $162 \AA$ (Figure 9 ). Another unexpected feature is the large rise in the background continuum emission, from $5-10$ counts at $2 \mathrm{~mm}$ to -200 counts at $10 \mathrm{~mm}$. These features raised concerns about the homogeneity of the plasma along its length . Specifically, were the level populations in the region of the $2 \mathrm{~mm}$ plasma viewed by the spectrometer identical to the conditions in the $10 \mathrm{~mm}$ section? As shown in Fig. 4, the 2,6 and 10mm sections shared a common boundary on the spectrometer end of the target wheel. To test if the plasma was homogeneous a target was built with the $2 \mathrm{~mm}$ sections on both ends of the target and the $6 \mathrm{~mm}$ section on the end of the target away from the spectrometer. First the conditions were arranged so as to reproduce the previous $10 \mathrm{~mm}$ spectra and then the emission from the two $2 \mathrm{~mm}$ sections at each end of the target was compared. It was immediately apparent that there 
was a large difference in intensity between the $2 \mathrm{~mm}$ section at the spectrometer end ard the $2 \mathrm{~mm}$ section at the opposite end. Taking the average of the $2 \mathrm{~mm}$ results. the best fit to the data was now a linear increase in intensity with length as shown in Fig. 10. The reason for the non-uniformity lay in a small angle between the target surface and the region vlewed by the spectrometer (Fig. 11), possibly caused by refraction. To verify this, the target was rotated about a vertical axis to change the position of the plasma generated by the two $2 \mathrm{~mm}$ sections with respect to the region viewed by the spectrometer. $W_{i}$ ith a $2^{\circ}$ rotation the AlXI $154 \AA$ emission from the two ends became equal. In this configuration however the length dependance of the emission was linear. In conclusion; the non-linear increase in Figs 5-8 was caused by geometrical effects and not by stimulated emission.

As noted before the measurement of an exponential intensity increase with length is commonly regarded as conclusive evidence for gain (see for instance ref $\varepsilon$ ). However in view of the above results it is clear that while this may be an encouraging sign of gain it is by no means sufficient proof that gain is present. As was done in some earlier works ( for example references 1. 4, 7, 11), it is critical to monitor the ernission from nearby spontaneous emission lines in the same ion, preferably lines with the same lower level as the lasing line, to be assured that one is viewing a homogeneous plasma and that the comparison of plasmas of differing lengths is a valid. This is particularly important for measurements of low gain lengths, GL $\leq 4$, where the enhancement of stimulated as compared to spontaneous emission is less that an order of magnitude. 


\section{Acknowledgements}

We would like to thank $\mathrm{E}$ Valeo for assistance with the gain fitting computer program and $J$ Schwarzmann for the target fabrication and $G$. Howe for assistance with the streak camera. We would also like to acknowledge N. M. Ceglio, D. P. Gaines, G. L. Howe, and E. S. Utterback of the LLNL Advanced X-ray Optics Program for providing TGSS for time resolved spectral measurements. This work was supported by the U.S. Department of Energy. Advanced Energy Projects of Basic Energy Sciences. 


\section{Figure Captions}

Fig. 1 The rotatable target system.

Fig. 2 Spectra obtained with $6 \mathrm{~J}$ laser energy from carbon plasmas of length:

(a) $1 \mathrm{~mm}$, (b) $2.5 \mathrm{~mm}$ and (c) $4.5 \mathrm{~mm}$.

Fig. 3 Intensities of the CVI $182 \AA$ and CVI $135 \AA$ lines versus plasma length and ( dashed line) a least squares fit to the gain equation (eqn. 1) with a gain of $4.5 \mathrm{~cm}^{-1}$ for the $192 \mathrm{i}$ line.

Fig. 4 Improved experimental set-up for gain mieasurements showing the range of angular adjustments available.

Fig. 5 Aluminum spectra obtained at 6. laser energy with target lengths $2 \mathrm{~mm}$ and $10 \mathrm{~mm}$.

Fig. 6 Dependence of the AlXI $154 \AA$ and AlX $177 \AA$ axal line intensity on length. The line represents a fit of the experimental points to the theoretical gain equation ( eqn. $I$ in the text).

Fig. 7 Spectra obtained at $12 \mathrm{~J}$ laser energy with เarget lengths $2 \mathrm{~mm}$ and $10 \mathrm{~mm}$. Note the $\mathrm{x} 10$ scale change from the $2 \mathrm{~mm}$ to $10 \mathrm{~mm}$ graph.

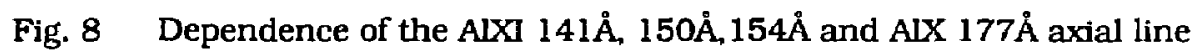
intensity on length. The line represents a theoretical fit of the experimental points to the gain equetion ( eqn. 1 in the text).

Fig. 9 Detailed time histories of (a) $154 \AA$ and (b) $162 \AA$ emission taken with $12 \mathrm{~J}$ of laser energy. The fluctuations are caused by film grain. 
Fig. 10 (a) data sho:ving the $154 \dot{A}$ intensity varlation with length but in thits case including $2 \mathrm{~mm}$ sections from both ends of the target. The $6 \mathrm{~mm}$ data was from a section at the opposite end of the target to the data in Figs 5-8. (b) as above but with the target rotated by $2^{\circ}$.

Fig. 11 Illustration of the effect of a small angle between the plasma and the region viewed by the spectrometer. The comparison of plasmas of differing lengths cannot be used for measuremenis of gain in this case. 


\section{References}

1 C.H. Skinner, D.S. DiCicca, D Kim, R.L. Rosser, S. Suckewer, A.P. Gupta, and J.G. Hirschberg J. Micros. 1989 in press. D. L. Matthews, P. L. Hagelstein, M. D. Rosen, M.J. Eckart, N.M. Ceglio, A. U. Hazi, J. Medecki, B. J. MacGowan, J. E. Trebes, B. L. Whitten, E. M. Campbell, C. W. Hatcher, A. M. Hawryiuk, R. L. Kaufman, L. D. Pleasance, G. Rambach, J. Scofield, G. Stone, and T. A. Weaver, Phys. Reu. Lett. 54, 110, (1985) and C.J.Keane, N.M.Ceglio, B. J. MacGowan, D. L. Matthews, D. G. Nilson. J. E. Trebes, and D. A. Wilson UCRL Preprint 100546, Feb 1989 submitted to $J$. Phys $B$. S. Suckewer, C. H. Skinner, D. Kim, E. Valeo, D. Voorhees, and A. Wouters Phys Rev. Lett. 57, 1004, (1986). D.KSim, C.H. Skinner, G. Umesh, and S. Suckewer Optics Letters, 14. 665-667, 1989.

S. Suckewer X-ray laser Related Experiments and Theory at

Princeton OSA Proceedings on Short Wavelength Coherent Radiation: Generation and Applications 2, 36. (1988). based on the RNLIN subroutine in the IMSL STAT/LIBRARY p239. G. Jamelot, P. Jaeglé, A. Carillon, F. Gadi, B. Gauthè, H. Guennou. A. Klisnick, C. Möller, and A. Sureau, I.E.E.E. Trans on Plasma Scierıce. 16, 497, (1988). T. Hara, K. Ando, N. Kusakbe. H. Yashiro. and Y. Aoyagi Jpn. J of Appl. Phys. 6, 1010-1012, (1989). 
9 J.L.Schwob, A. Wouters, and S. Suckewer, Rev. Sci. Instrum. 58, 1601. (1987).

10 N.M.Ceglio in Laser Interaction and Related Phenomena. H. Hora and G. Miley.eds., 7. 39, Plenum Press, New York, 1986. In the present work the TGSS was used without the imaging mirror described in this reference.

11 S. Suckewer, C. H. Skinner, D. Kim. E. Valeo, D. Voorhees, and A. Wouters Phys Rev. Lett. 57, 1004, (1986) and D. Kim. C. H. Skinner. A. Wouters, E. Vaieo, D. Voorhees and S. Suckewer J. Opt. Soc. Am B 6. $115,1989$. 
\# 89x0674

年

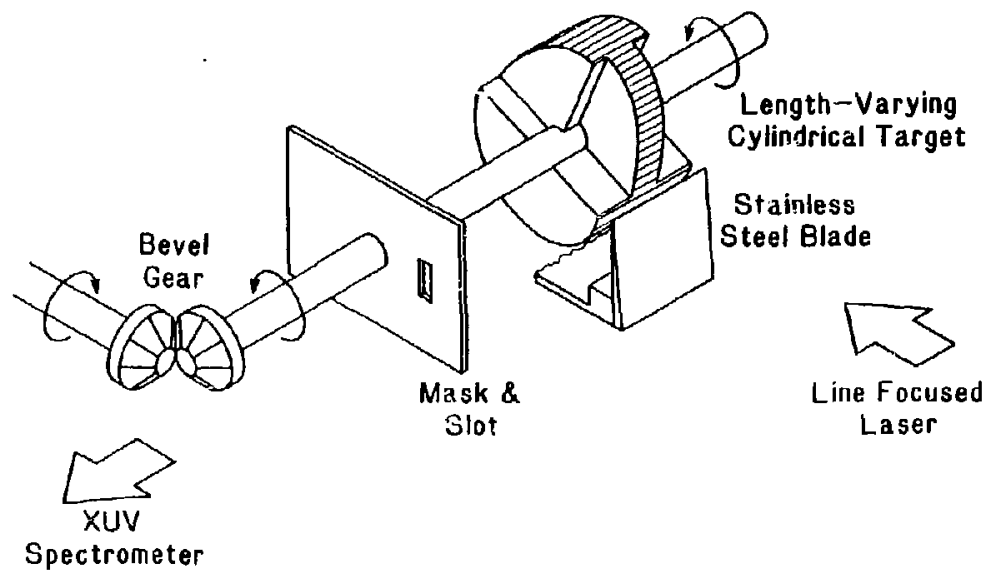



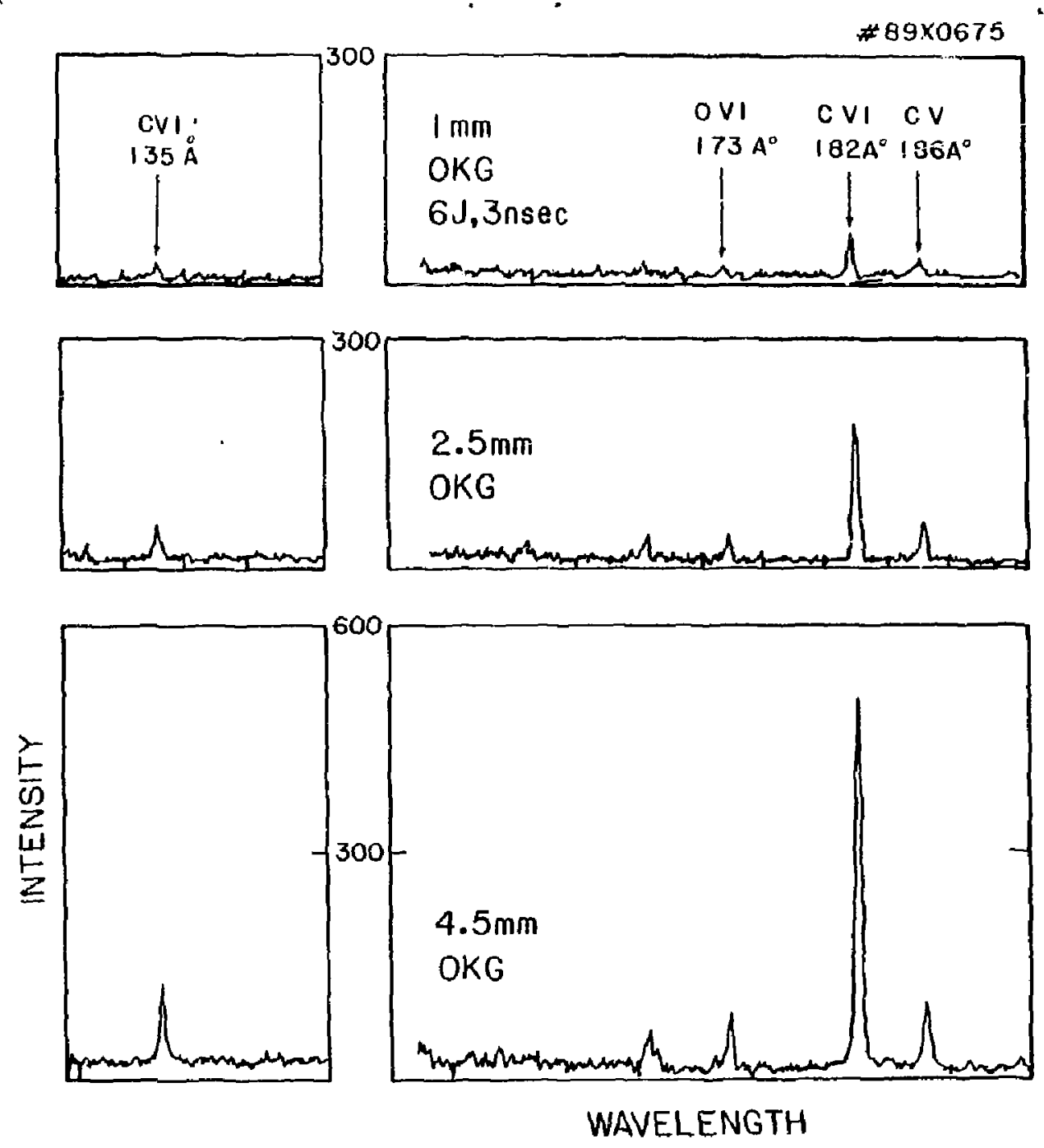


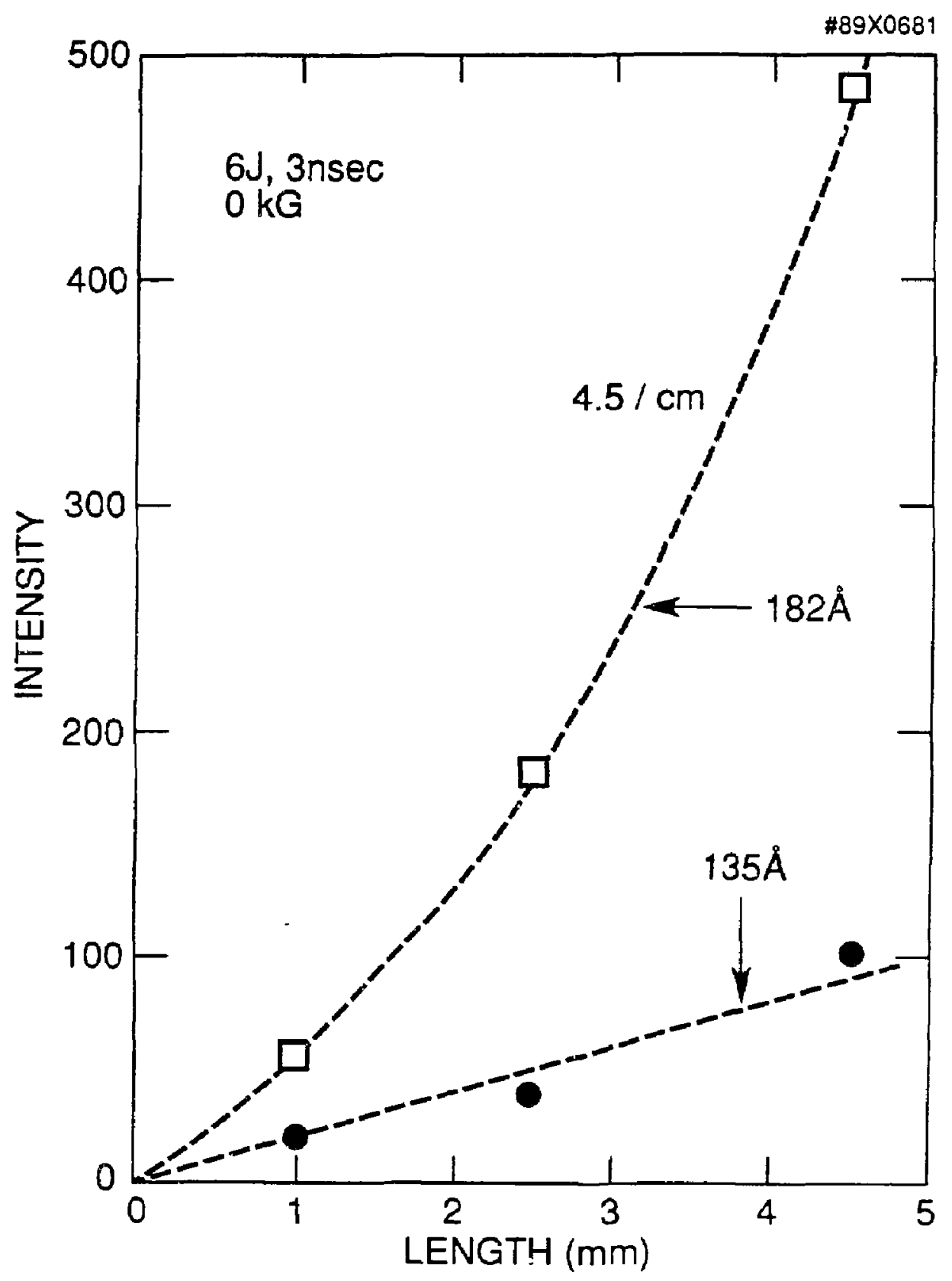

Fig. 3 


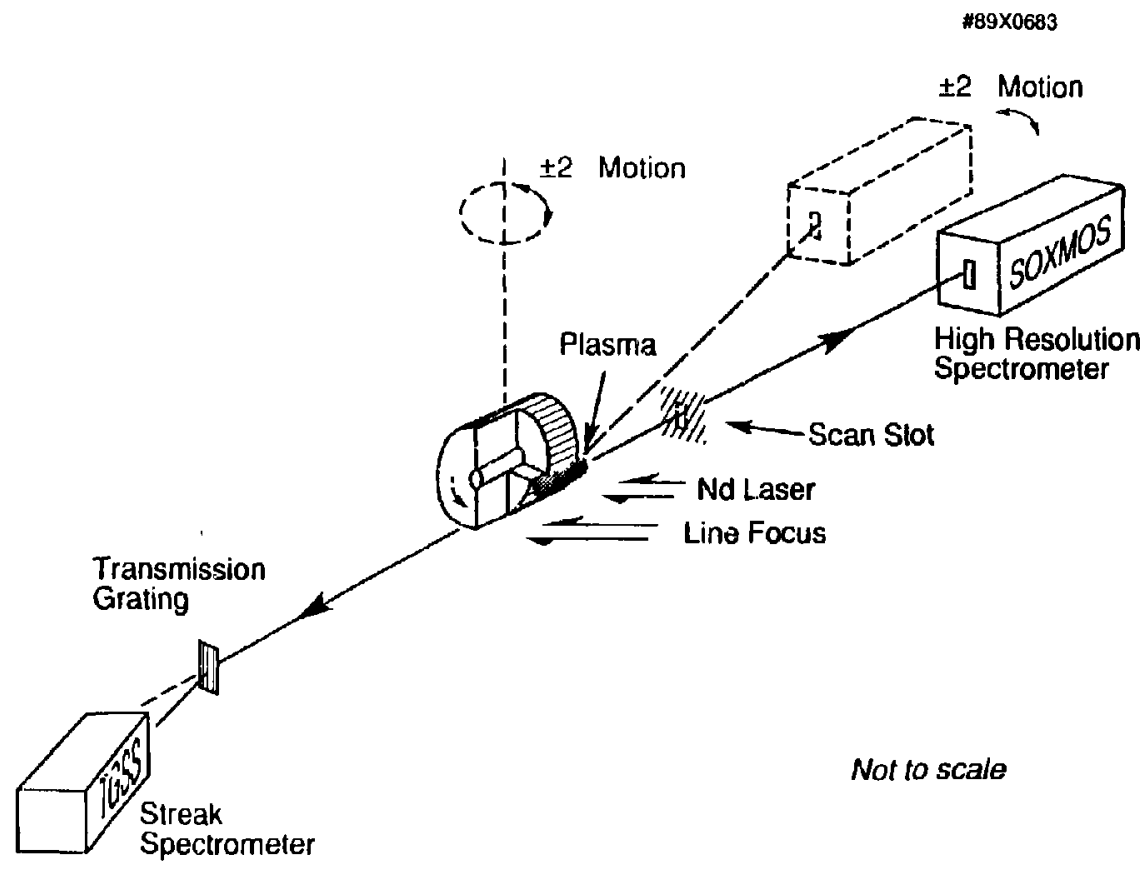



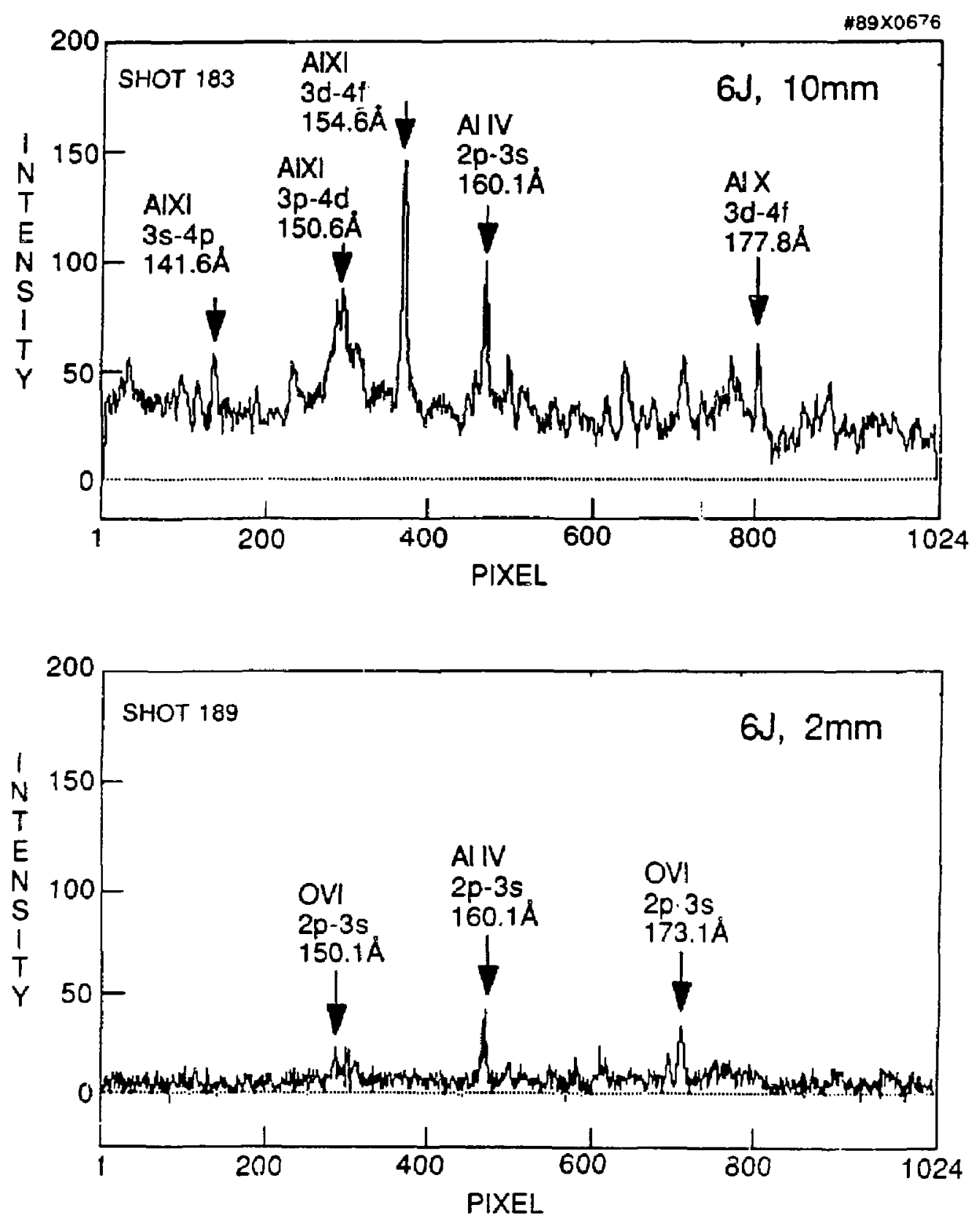

Fig. 5 

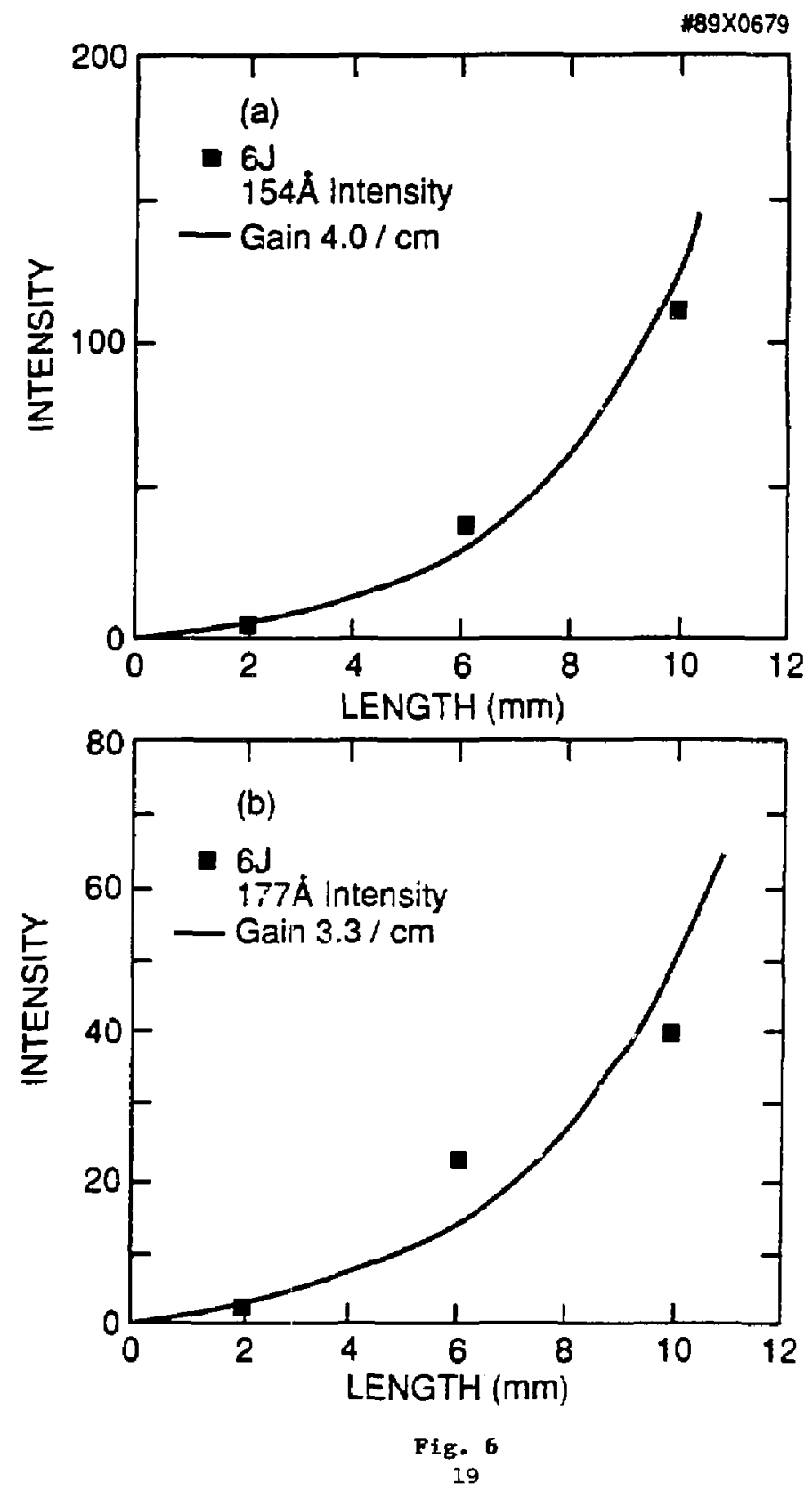

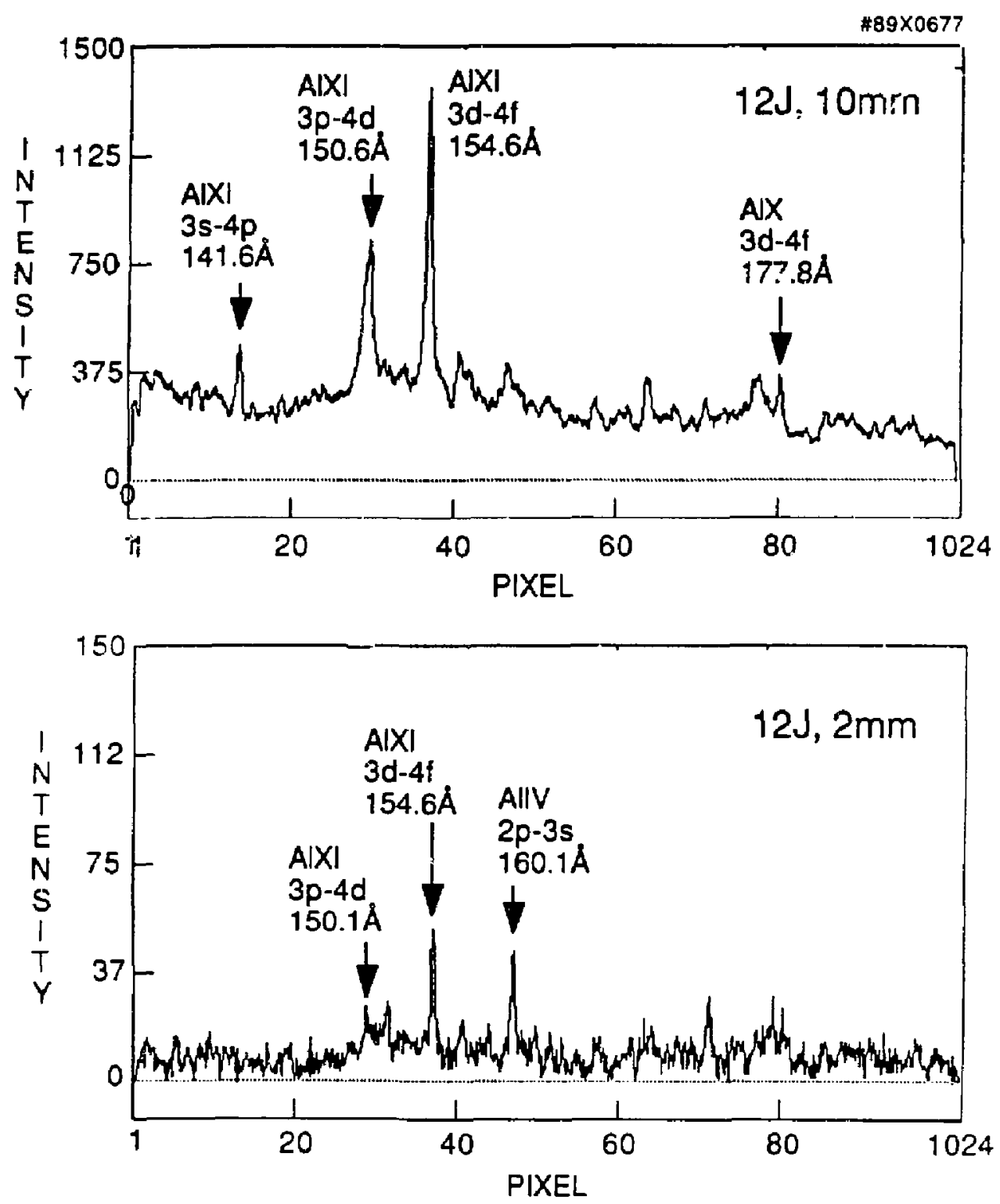

Fig. 7 


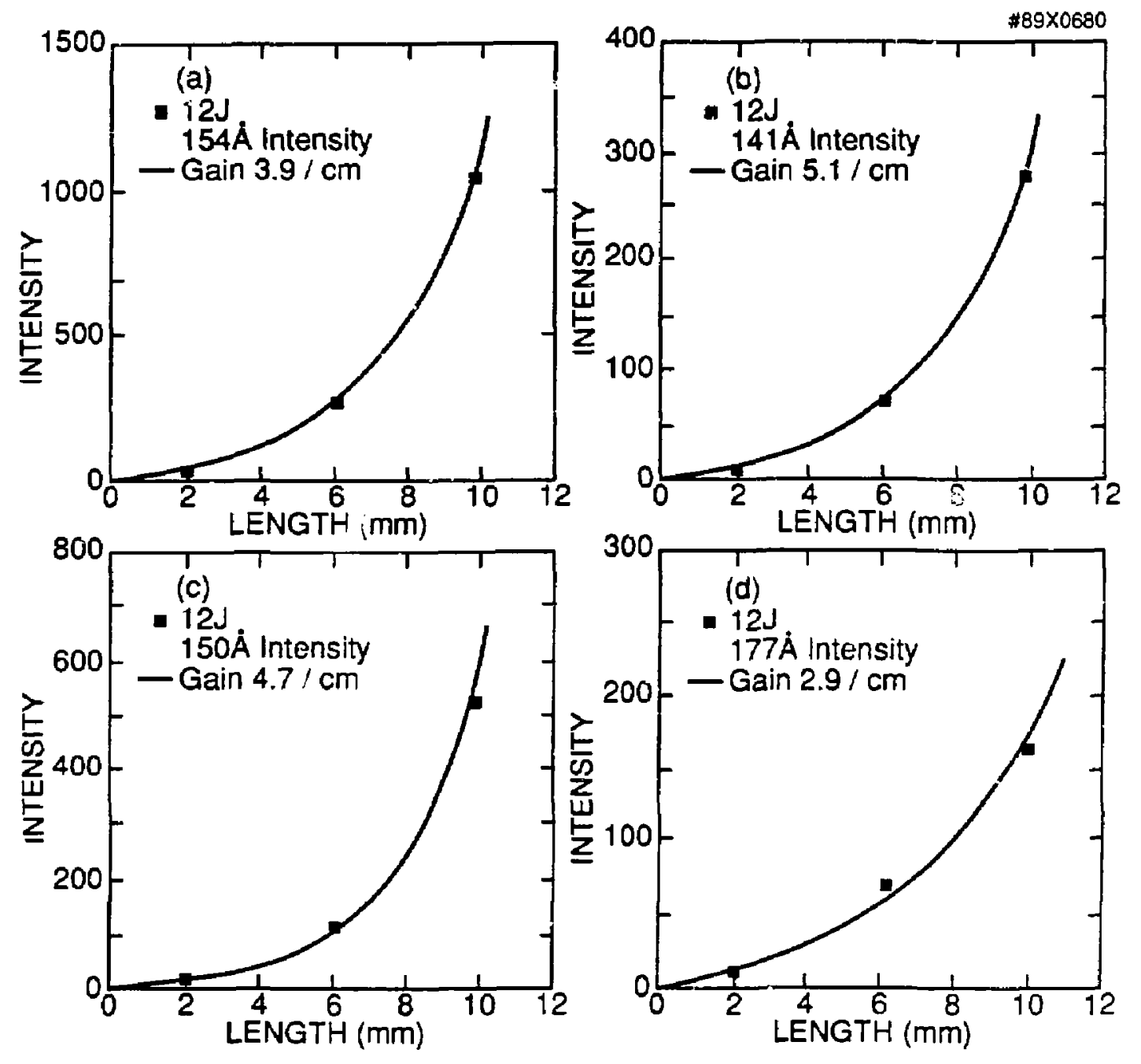

Pig. 8 


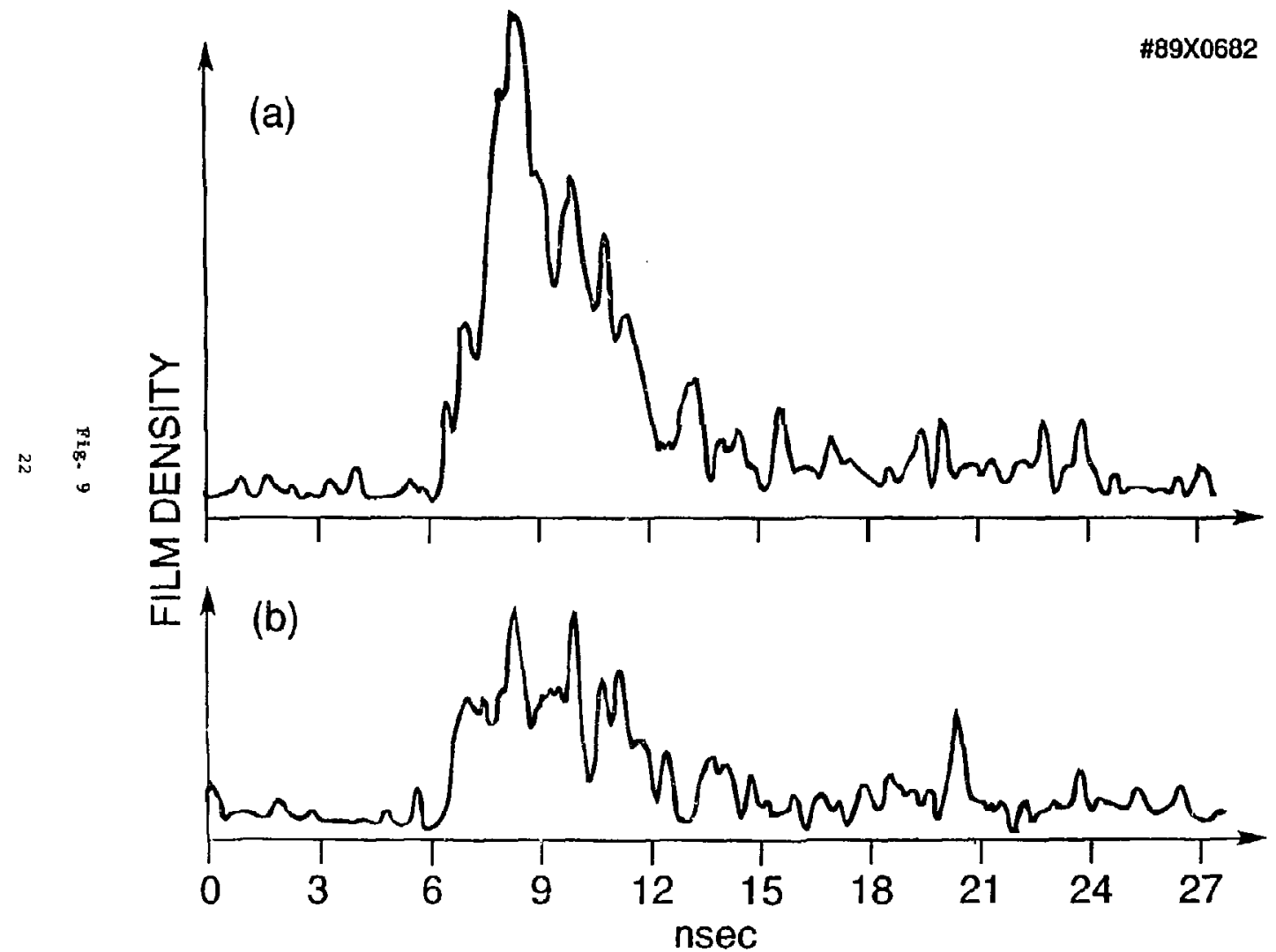



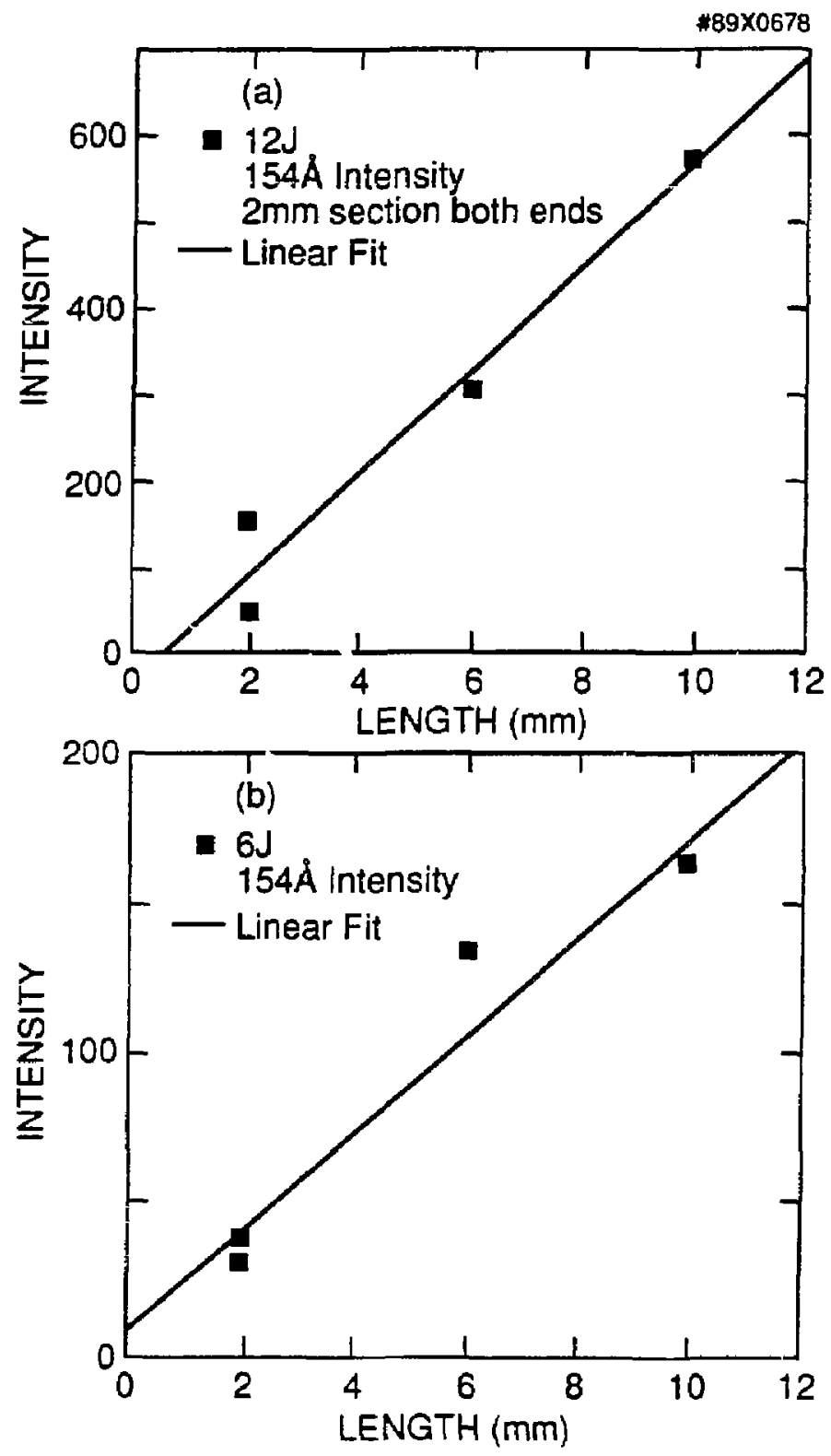

Pig. 10 

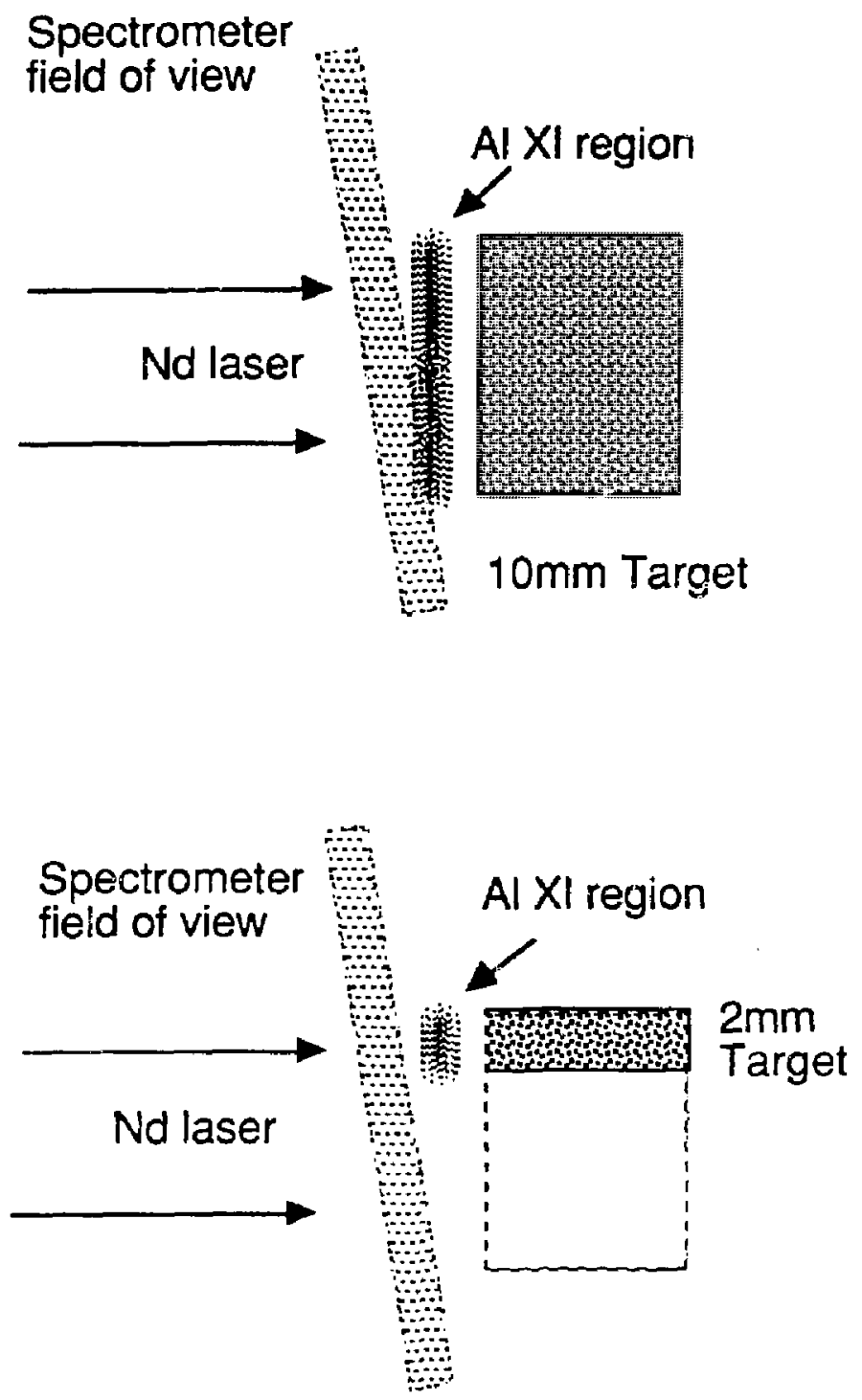